\title{
Twenty-One
}

\section{DO WE HAVE AN OBLIGATION TO MAKE SMARTER BABIES?}

\author{
Lisa Bortolotti
}

\section{Introduction}

In this chapter I consider some issues concerning cognitive enhancements and the ethics of enhancing in reproduction and parenting. I argue that there are moral reasons to enhance the cognitive capacities of the children one has, or of the children one is going to have, and that these enhancements should not be seen as an alternative to pursuing important changes in society that might also improve one's own and one's children's life. It has been argued that an emphasis on enhancing cognitive capacities might encourage the commodification of children. But this objection seems misplaced. The reasons why one decides to reproduce can be subject to moral approbation or condemnation, as such reasons might be indicators of the quality of one's parenting and the happiness of the future persons one is committed to bringing to life. However, once the decision to reproduce is made, no further harm comes from taking as few risks as possible on behalf of the persons to whom one is giving life with their health, character and cognitive capacities.

In his 2004 paper "If you must make babies, then at least make the best babies you can?" Matti Häyry (2004) ${ }^{1}$ defends three claims: (1) that to have children is not necessarily good or rational; (2) that it would be good and rational to make sure that the children we do have have the best possible lives; (3) that it is not easy to judge whether scientific advances (e.g. the possibility of embryo selection by IVF) or social changes are the best means to achieve this outcome. On the basis of a harmed-condition account of disability, I shall challenge the assumption, implicit in (3), that conferring benefits by enhancements and by social change are mutually exclusive. Then I shall argue in favor of (2) and dismiss some common objections to cognitive enhancements (safety, allocation of resources and diminished agency). I shall also discuss the view according to which the adoption of enhancing strategies in reproduction and parenting is an instance of a general tendency towards the commodification of children. In working out what commodification entails, I shall argue in favor of (1), but from a different perspective from Häyry's. I shall claim that 
the motivation people have to reproduce might be more or less morally acceptable, but once the decision to reproduce is made, no further harm can come from enhancing the (future) child's capacities.

\section{Moral Reasons for Enhancing}

In this chapter I defend the view that we have moral reasons to enhance. The basis for my defense of enhancements is the principle of beneficence, according to which people have a moral obligation to prevent harm and to confer benefits when it is possible. But the presence of moral reasons to enhance does not imply that people have any moral obligation to use any specific enhancement strategy in conferring benefits to their (future) children. An "enhancing strategy" is any activity that aims at preventing harm and conferring benefit. On this account, organizing music instruction for one's children when they are aged 3-9 is an enhancing strategy, if it is true that there is a correlation between music instruction in young children and increased spatio-temporal and mathematical abilities. $^{2}$

There is a gulf between recognizing moral reasons to enhance and arguing that we should be morally obliged to adopt one specific enhancing strategy in reproduction or parenting. And that is why the debate on enhancements cannot be exhausted by an appeal to beneficence and the harm-benefit continuum. There are pressing questions that must be raised and answered. How powerful are the moral reasons we have for enhancing? Are there any moral reasons against enhancing as such? What are the risks and costs involved in enhancing? Are there any moral reasons against any specific enhancing strategies? For instance, Häyry ${ }^{3}$ discusses one objection to embryo selection in assisted reproduction as enhancing strategy. The process necessary for assisted reproduction might place an unnecessary burden on women, who would be required to go through extensive testing and potentially distressful or painful procedures. All these considerations must be taken into account in our decisionmaking and only those measures that seem to have reasonable costs should be adopted in order to enhance.

\section{A. Disability}

In the so-called harmed condition account of disability, conditions are regarded as disabling if they are physical or mental conditions that are harmful to the individual. According to this account, disabling conditions constitute a disadvantage with respect to relevant alternatives, not necessarily with respect to the conditions of the typical human. The reason why the notion of normal species functioning is unhelpful in defining disabilities is that it would make disability too narrow. Changing environmental factors, or new discoveries about the onset of serious diseases, for instance, might make it the case that typical 
conditions of our species come to be regarded as disabling. Attention-deficit disorders, memory loss and Down's syndrome are disabling, because, to different extent, they cause harm to the people who are in them by exposing them to risks, impairing them in what they do, limiting their opportunities or preventing them from having experiences that are worthwhile.

This conception of disability is sufficiently broad to cover all the harmful conditions that we might intuitively regard as disabling, whether the harm be primarily caused by medical conditions of the person, cognitive, genetic or environmental factors or social context. Moreover, it has clear advantages with respect to a merely social conception of disability, as it is not committed to the rather implausible claim that all disabling features of the condition would disappear if society were inclusive and free from discrimination or prejudice. Whereas it is certainly true that certain attitudes in society towards people who are perceived as different cannot but make things worse for disabled people, in many cases, perhaps most cases, their condition would remain harmful once society had been reformed (think again about attention-deficit disorders, memory loss or Down's syndrome).

What do I mean by "harm" in this context? I would like to adopt a very broad conception of harm as the set-back of interests or preferences about states of affairs that significantly affect an individual's well-being. It could harm me not to be able to appreciate a spectacular sunset on the coast, because I would have an interest in enjoying that view. It would increase the quality and richness of my experiential life. It would have harmed me to be born in 1774 rather than in 1974, because I would have had limited capacity to exercise my autonomy in a society in which women were less likely to receive an education, participate in public life and make their own choices.

The adoption of the harmed-condition account of disability has important consequences for our way of conceiving reproductive and parental choices. Once we accept that disabling conditions are harmful to the individual (by definition), it is easy to see that we have moral reasons to prevent disabling conditions if possible or reduce their harmful effects, as part of our commitment to the basic moral principle of avoiding unnecessary harm. But, again, this says nothing about the way in which these moral reasons might impact in practice on our choices. One might recognize the presence of moral reasons to prevent disabling conditions or reduce their harmful effects and still object on moral or other grounds to the methods by which the obligation can be carried out given a rational costs/benefits analysis. Moreover, the strength of the moral reasons we have to prevent disabilities might be thought to vary in accordance with the context of the disabling condition, and in accordance with the degree of harm that the disabling condition is likely to cause to (future) children. Many feel that we have a moral obligation to prevent a serious disability, but do not feel the same about a minor disability, which is going to cause just a slight inconvenience. 


\section{B. The Continuum between Harms and Benefits}

If we accept that there are moral reasons to prevent or eradicate disability when possible, does this commit us to recognize that we also have moral reasons to enhance? Many have the intuition that there are moral reasons to avoid harm by preventing our children from being in disabling conditions, but view enhancements with suspicion. This intuition is an illusion for whoever is committed to the existence of the harm-benefit continuum. The harm-benefit continuum is the idea that "the reasons we have not to harm others or creating others who will be unnecessarily harmed are continuous with the reasons we have for conferring benefits on others if we can." $\mathrm{We}$ seem to have moral reasons to improve the conditions in which others find themselves, whether these conditions are disabling or not. The reasons we have to avoid harming others are continuous with the reasons we have for conferring benefits on others if we can, because all actions are re-describable as omissions and vice versa. ${ }^{6}$

This is supported by the intuitive analogy between disability and enhancement. If disabling conditions constitute a disadvantage with respect to some relevant alternatives, enhanced conditions constitute an advantage. Let me offer an example. Research suggests that patients who suffer from sleep deprivation are at risk of developing cognitive and emotional difficulties, are slower at solving math's problems and processing language and are much more prone to accidents when driving. Some amphetamines are used to counterbalance the effects of sleep deprivation and they do so by improving attention, concentration, spatial working memory, and planning and have been long used by the US military for these purposes. ${ }^{7}$ Drugs that are safer and nonaddictive can have similar effects and could be used not to counteract the effects of a disabling condition but to improve performance, e.g. to help students perform well during examinations. It might seem uncontroversial to grant that an improved cognitive performance would constitute an advantage on the assumption that the enhancing drugs are safe, but some maintain that there are moral objections to using drugs for this purpose. Some are concerned that there is less worth in achieving an objective such as passing an examination if one relies on the effects of chemical substances on one's brain, or that unfairly distributed advantages will deeply affect an already unjust society. I am going to discuss these interesting objections to enhancements in the next section.

\section{Changing Society}

But before let me go back for a second to the moral justification of enhancements in reproduction and parenting. Some might feel that, although there are moral reasons to confer benefits, adopting enhancing strategies to do so is not the best available course of action, as it precludes other, less controversial, 
ways of doing it. For instance, Häyry ${ }^{8}$ presents the promotion of social changes as an alternative to enhancement if one wants to improve the life of one's (future) children. But I cannot see how changing society and improving conditions in an individual would ever be mutually exclusive or even competing courses of action. If I have a child who is cognitively impaired, I might want to act on the surrounding social environment with the hope that, as a consequence, he will be better accepted by his peers and that he will receive more support from his teachers, but my commitment to changing society for the better is not incompatible with reducing the harm that the disability is causing to my child by intervening on his disabling condition. Similarly, in the case of a prenatal test revealing that my future child will have such a disability, I might want to take measures to prevent or reduce its potential effects on him and at the same time strengthen my commitment to creating a fairer world around him. In the circumstances in which the disability is so serious that parents come to believe that their future child will not have a life worth living, they might decide to terminate the pregnancy. But even in these extreme circumstances, it is not clear to me that they are confronted with a choice between changing society or changing the individual, or that they are sending any negative messages to other parents in similar circumstances who have taken a different course of action.

\section{Moral Reasons Not to Enhance}

\section{A. Safety}

In the bioethical literature, the press, and even in recent cinematography, enhancements are viewed with great suspicion. First, there are concerns about the safety of the procedures involved. Second, there are worries about the limited amount of knowledge even experts have about the consequences of, say, genetic engineering in cognitive domains. In Daniels (2005) we find an interesting example. ${ }^{9}$ Suppose that we learn that an enhancement of short-term memory would benefit many of our cognitive processes and that we have the opportunity to enhance short-term memory by operating on embryos. Daniels argues that we should not do it because we would not be able to predict the consequences of enhancing memory performance. Daniels' concern is that enhancements might not really improve the quality of life. He is not just reiterating the idea that there are always risks involved in changing something that is working well enough. He is saying that, given the nature of certain modifications and the complex way in which we would need to assess their consequences, the fact that the capacity or trait to be enhanced is a necessary condition for better performance does not mean that by enhancing it we would produce an overall better offspring. Another example of this phenomenon is the study that has been conducted at the University of Pennsylvania on mice. Mice 
which had been genetically engineered to improve their memory and learning were then shown to be unusually sensitive to pain. ${ }^{10}$

Safety concerns should definitely be taken into account, and it is reasonable to assume that a careful risk/benefit analysis would not recommend many procedures that aim at enhancing complex cognitive functions at this stage. This fact, though, does not seem relevant to deeming enhancements per se unethical. What would be unethical is to risk people's health by enhancing their cognitive performance if the foreseen benefit is not worth the risk. Of course, separate issues are whether we can obtain non-biased information about safety, how the risk/benefit ratio should be calculated and by whom. It is a platitude that the perception of risk might vary and that some people might value the achievements made possible by enhanced conditions more than others. It is reported that many athletes would take a drug that would enable them to win every competition for a few years, even if the drug shortened their life significantly. ${ }^{11}$

\section{B. Limited Resources}

Safety aside, some people are worried about unfair allocation of resources. It is a common thought that some enhancing strategies such as genetic engineering are going to be very expensive and that only the better-off in society will be able to afford them. As a consequence, the current divisions in society will become even less bridgeable. Notice that this is not an ethical objection to enhancing as such, but a concern about the unfair distribution of resources. Actually, the worry about the ways in which enhancements will be distributed implies that enhancements are perceived as a good thing. The problem of resource allocation is an extremely urgent one, but it is not specific to cognitive enhancement in any interesting way. For all the available resources which can be seen as beneficial to humans (e.g. food, education, therapies etc.), there is an unfair distribution in society. If cognitive enhancements are going to be a further available resource, the problem of access would apply to them too. Mehlman suggests a way in which some fair access could be promoted:

A better approach would be to permit cognitive enhancements to be available on the open market for those who can afford them and to subsidize access to them for those who cannot. ... By making these products widely available, society would gain the benefits of achievements they made possible and reduce or at least refrain from exacerbating the inequalities that stemmed from differences in wealth. ${ }^{12}$

Policy regulations and issues of state intervention in the research on cognitive enhancement and the availability of enhancing strategies will have to be thought out by paying attention to short- and long-term consequences, but 
these measures would not and do not amount to an objection to enhancing on the basis that enhancing is unethical.

\section{Diminished Agency}

Finally, some believe that the practice of enhancing and genetically engineering capacities will lead to a revision of our conception of agency. ${ }^{13}$ Agents typically enjoy a certain amount of freedom of action and are subject to judgments of praise for their achievements and of blame for their failures. But if the physical or intellectual achievement of the agent is only marginally due to effort and discipline and mainly due to the effects of, say, a powerful drug, the achievement might no longer be a good reason to admire the agent. The argument is supposed to show that a pervasive use of enhancement might lead to a diminished sense of agency and responsibility.

To assess the force of this argument one needs to be able to account for what the consequences of the practice of enhancement would really be for our conception of agency. Partly, this is an empirical question. We know what our current psychological reactions to illicit drug-taking by athletes are; we feel it is cheating. But the scenario in which everybody is given an opportunity to enhance some of their conditions safely is significantly different and our reactions would almost certainly reflect that difference. It is not at all obvious that we would lose the sense of ownership of our own actions if the capacities that made it possible for us to achieve something desirable had been enhanced. One possible consequence of pervasive enhancement could be a "raising the bar" effect that would subtract little to the merits of the personal achievements of the individual.

That said, it seems as if the diminished agency objection is on to something. Suppose you are a runner and want to increase your speed by $20 \%$. Also suppose that there are two methods by which you can achieve this target. You can take a pill that has an immediate enhancing effect on your speed or you can train for two months, three hours a day. Notice that these are both enhancing strategies if we define enhancements on the basis of their predicted outcomes. Now, you might have a morally relevant reason to prefer the hard way to the easy way. You might value self-discipline and think that you will grow as a person if you achieve this target by making a conscious effort to perfect your body during the next two months. You might believe that the sense of satisfaction you would get at the end of the training for having achieved the target is worth the time and the effort that are required. But all these considerations do not amount to judging that it would be unethical for you to choose the easy option.

An analogous case can present itself when we are considering the ethics of enhancing cognitive capacities or cognitive performance in the context of reproductive choices. To give a child the opportunity to learn how to play a 
musical instrument might be regarded as important, because receiving music instruction is a valuable experience independently of its alleged effects on memory and mathematical skills. It is valuable because it is formative, it is social and it might install certain values in the child, such as the idea that hard work pays off and that almost nothing rewarding in life comes cheap. If there was a magic pill that could produce the same enhancing effects immediately, would it be unethical to administer it to a child? The enhancing pill is not equivalent to music instruction, because taking the pill is not a formative experience, but it would not be unethical either. Moreover, some children do not get any pleasure out of studying music and would not respond positively to music instruction. For them, one could argue, taking the pill would not be a worse option. Their cognitive capacities would be enhanced to the same extent by hypothesis, and they would always have the opportunity to get the other benefits associated with music instruction from other formative and social experiences in their lives.

\section{Commodification of Children}

Häyry (2004) reviews the reasons why people make a conscious decision to have babies in spite of the obvious fact that the future persons they generate might suffer in the course of their lives. The assessment of the reasons for reproducing is not the main concern of this paper, but I need to address another common ethical objection to enhancing in reproduction, the so-called commodification of children, and the rationality of reproduction and commodification are importantly related issues. One of the most popular objections to enhancing one's children's cognitive capacities is that it encourages parents to conceive of their children as commodities, as objects that have a value not in themselves but as means to achieve something else. Why do people want trendier clothes, cars or mobile phones? Because their aesthetic properties reflect on the image of the person who owns them. One might argue that to want a smarter child is an instance of the same kind of behavior. Parents, actual or prospective, might regard their children as a means to achieve status, as something to boast about, and not as persons whose life is valuable in itself.

My view is that, once one makes the important decision to have children, there are moral reasons to do whatever is in one's power to make sure that one's children will have a happy life. This might include enhancing their cognitive abilities by methods that one finds acceptable given their risks and costs. Obviously, there are many things one cannot have control over and one can never have any certainty that one's children will be happy people. This is presumably why Häyry concludes that it is irrational to reproduce. But to claim that there are moral reasons to enhance is not sufficient to dismiss the commodification objection. The way in which parents conceive of their children has moral relevance and should be discussed, but not just in relation to en- 
hancement. The commodification of children as an objection to enhancing in reproduction is misplaced, as it should be viewed as an objection to reproduction tout court.

It is often thought that people should not have merely "selfish" reasons to reproduce. The way they conceive of their children might be an indicator of poor parenting skills and might affect their capacity to bring about their children's happiness as well as their own. (This is an empirical claim and as such needs to be supported by evidence, but it has some initial plausibility.) We experience uneasiness when we read interviews to successful career women in their late thirties or early forties who declare that the only thing missing in their lives is a child, as if reproducing were the answer to a need for variety of experiences in one's life or another target to tick off on an imaginary list of things to achieve by a certain age. Our uneasiness does not necessarily track the presence of wrongdoing. After all, people might have equally respectable and yet different reasons to make the choice of having children and personal realization is likely to play a role in almost all the life-changing decisions we make. However, my point is that, if there is a commodification of children objection to reproduction, it is certainly not confined to the practice of enhancement. Commodification seems to be a complex phenomenon whose origin can be found in the motivations people have to reproduce and whose manifestations can vary. Refraining from enhancing would not necessarily contribute to changing such a conception of children.

\section{Conclusion}

In this chapter I have argued that people have moral reasons to enhance the cognitive performance of their children on the basis of the principle of beneficence and subject to an evaluation of the risks and costs of the chosen enhancing strategies. To further support my argument, I have defended three claims: (1) the practice of enhancement does not rule out the attempt to better one's children's life by changing society and in particular by eliminating prejudice against diversity; (2) the objections to enhancement that concern safety, allocation of resources and diminished agency do not seem to offer moral reasons against enhancements per se; (3) the common thought that enhancing might promote a view of children as commodities seems confused. The commodification of children is a social phenomenon of which enhancement can be a manifestation, but which has its roots in the morally dubious reasons people might have to reproduce and which can manifest itself in numerous other ways. 


\section{ACKNOWLEDGEMENTS}

I am indebted to John Harris for a thorough discussion of the relation between disability and enhancements and to Matteo Mameli for very useful feedback on the arguments I have defended here. I also acknowledge the stimulus and support of the EURECA project in the preparation of this paper. The project EURECA on delimiting the concept of research and research activities was sponsored by the European Commission, DG-Research as part of the Science and Society research programme $6^{\text {th }}$ Framework.

\section{NOTES}

1. Matti Häyry, "If You Must Make Babies, Then At Least Make the Best Babies You Can?" Human Fertility, 7:2 (2004), pp. 105-112.

2. Lois Hetland, "Learning to Make Music Enhances Spatial Reasoning," Journal of Aesthetic Education, 34 (2000), 179-238; Amy Graziano, Matthew Peterson and Gordon Shaw, "Enhanced Learning of Proportional Math Through Music Training and Spatio-Temporal Training," Neurological Research 21:2 (1999), 139-152.

3. Häyry, "If You Must Make Babies, Then At Least Make the Best Babies You Can?" p. 111.

4. Lisa Bortolotti and John Harris, "Disability, Enhancement and the HarmBenefit Continuum," Freedom and Responsibility in Reproductive Choice, eds. J. Spencer and A. Pedain (Oxford and Oregon: Hart Publishing, 2006), pp. 31-49.

5. John Harris, "One Principle and Three Fallacies of Disability Studies," Journal of Medical Ethics, 27 (2001), pp. 383-387, p. 386.

6. Jonathan Glover, Causing Death and Saving Lives (New York: Penguin, 1977). John Harris, Violence and Responsibility (London: Routledge \& Kegan Paul, 1980).

7. Anjan Chatterjee, "Cosmetic Neurology: The Controversy Over Enhancing Movement, Mentation and Mood," Neurology, 63 (2004), pp. 968-974, p. 969. Maxwell Mehlman, “Cognition-Enhancing Drugs," The Millbank Quarterly, 82:3 (2004), pp. 483-506, p. 484

8. Häyry, "If You Must Make Babies, Then At Least Make the Best Babies You Can?" pp. 109-111.

9. Norman Daniels, "Can Anyone Really Be Talking About Ethically Modifying Human Nature?" The Enhancement of Human Beings, eds. Julian Savulescu and Nick Bostrom (Oxford: Oxford University Press, 2005).

10. Ya-Ping Tang, Eiji Shimizu et al., "Genetic Enhancement of Learning and Memory in Mice," Nature, 401 (1999), pp. 63-69; Ya-Ping Tang, Eiji Shimizu et al., "Do 'Smart' Mice Feel More Pain or Are They Just Better Learners?" Nature Neuroscience, 4:5 (2001), pp. 453-454.

11. Mehlman, "Cognition-Enhancing Drugs", p. 487.

12. Ibid., p. 499.

13. Michael Sandel, What's wrong with enhancement, Council of Bioethics, http://www.bioethics.gov.background.sandelpaper.html (2002). 